\title{
El sistema de seguridad interamericana y sus nuevos desarrollos a través del Tratado de Tlatelolco*
}

El objetivo de este estudio no es analizar el sistema de seguridad interamericana en sí mismo, aun cuando con imaginación se pudiese encontrar alguna aproximación no utilizada hasta la fecha ${ }^{1}$. Bástenos recordar que lo que se ha conocido como "sistema de seguridad interamericana", ha supuesto la conjunción de varios presupuestos básicos tales como: condenación del recurso a la fuerza; obligación de resolver pacíficamente las controversias; solidaridad continental frente a la agresión y determinación, por último, de una zona de seguridad o esfera espacial de aplicación, como la llama Pedro F. Salas ${ }^{2}$.

En relación a estos cuatro presupuestos básicos, los dos primeros aparecen como intangibles en una comunidad o sociedad internacional que ha valorizado el principio de la "prevención de la guerra y la substitución de la violencia en las relaciones internacionales por el derecho mundial"3.

Los otros dos, solidaridad continental y determinación de una zona de seguridad, pueden sufrir variaciones, que utilizando una terminología neutra, podemos denominar intrínsecas y extrínsecas.

Es un hecho que el concepto de solidaridad ha variado por razones imputables a todos los actores del sistema, sean éstos los Estados Unidos de Norteamérica o los diversos países de América Latina. Para los primeros no existen razones específicas para sostener que América Latina está más íntimamente ligada que Europa o Asia y que por lo tanto, requiere de Washington una mayor participación en los asuntos regionales ${ }^{4}$.

* Este trabajo se realizó dentro de un programa de estudios sobre relaciones entre Amę́rica Latina, los Estados Unidos y Europa Occidental, bajo la dirección del profesor. Gustavo Lagos y con los auspicios de la Fundación Tinker.

'Un análisis evolutivo lo encontramos en el trabajo de Orrego (F)., "El sistema interamericano de seguridad colectiva" en la obra por nosotros editada, "Antecedentes, balance y perspectivas del Sistema Interamericano", Santiago, Editorial Universitaria, 1977. 243 págs., pp. 108-148.

${ }^{2}$ CF. El Tratado Interamericano de Asistencia recíproca de Rio de Janeiro (1947), Santiago, Editorial Jurídica de Chile, 1962, 291 págs., pp. 90 y siguientes.

${ }^{3}$ Cf. Clark (G) and Sohn (L), World peace through World Law., Cambridge, Massachusetts, Harvard University Press, 1966, 535 pp.

4 Véanse las declaraciones efectuadas en 1973 por William D. Rogers. Estas aparecen citadas en el artículo de Alejandro Magnet, "La'reforma de la Carta de la oEA" en la obra Antecedentes, balance y perspectivas ..., op. cit., pp. 87-107. 
Por el contrario, existen antecedentes que manifiestan un interés de parte de los Estados Unidos por reducir su presencia en organizaciones regionales ${ }^{5}$.

Por otra parte, los países latinoamericanos, críticos en su mayoría de la aplicación del sistema clásico de seguridad continental, pretenden ampliarlo al querer establecer formalmente la solidaridad económica interamericana. "La retórica tradicional —escribe Alejandro Magnetha incubierto hasta ahora, la ambigüedad de la situación y, fatalmente ha conducido al sentimiento de frustración generalizado en los países latinoamericanos con respecto a las relaciones interamericanas ${ }^{206}$.

A todos estos antecedentes habría que agregar otros elementos que inciden directamente en nuestro trabajo y que dicen relación con la seguridad estratégica de la región. Una de las ideas sobre las cuales se basa el Informe Linowitz es que América Latina no representa un peligro estratégico para la seguridad de los Estados Unidos y no se percibe ninguna amenaza seria, interna o externa, a la seguridad del Hemisferio Occidental ${ }^{7}$.

Por último, se percibe en la región intentos de independencia frente a un sistema verticál de relaciones y ofertas de transferencia de poderes por parte del líder regional. A este respecto cabe transcribir dos declaraciones pertinentes: la primera del Canciller de Bräsil efectuada en Chatham House (octubre de 1975), en donde Antonio Azeredo da Silveira decía "...un poder emergente, con una amplia variedad de intereses en muchos campos, no puede permitir una rígida alineación enraizada en el pasado, que limite su acción en la escena mundial"; la segunda, del secretario de estado Kissinger quien, en visita a Brasilia (febrero de 1976), se refería al Brasil como "...un pueblo que está tomando su lugar en la jerarquía de vanguardia de las naciones... Mi país - agregaba - le da la bienvenida al nuevo papel del Brasil en los asuntos mundiales ${ }^{28}$.

El contexto en donde se originó y en donde recibió mayor aplicación el sistema de seguridad interamericana ha variado, pues, enormemente. No olvidemos, por lo demás, que el Tratado Interamericano de Asistencia Recíproca de Rio de Janeiro fue reformada en San José de Costa Rica

\footnotetext{
${ }^{5}$ Proposiciones del Secretario de Estado Sr. Vance de disminuir la contribución de USA en el presupuesto de la OEA de un $66 \%$ a un $49 \%$.

${ }^{6}$ La reforma de la Carta de la oza., op. cit., p. 106.

${ }^{7}$ Véase el artículo de Vargas (R.). Estados Unidos y América Latina bajo la presidencia de Carter. Revista Estudios Internacionales, $N^{\circ}$ 41, enero-marzo 1978, pp. 83-119, p. 99.

${ }^{8}$ Estas declaraciones aparecen citadas en el artículo de Gall (N.), "Energía a tómica para el Brasil, peligro para todos", en Revista Estrategia $N^{\circ} 42$, septiembre-octubre 1976, Pp. 70-103.
} 
precisamente para impedir que se repitiera lo sucedido en la IX reunión de Consulta en donde se confundieron, no por primera vez, los términos de "agresión" y de "intervención".

En esta reforma se advierte igualmente el interés de los países latinoamericanos por apartarse del influjo y posición mundial de los Estados Unidos al permitir el recurso al Consejo de Seguridad de Naciones Unidas $^{9}$, y al pretender reducir la zona de seguridad que se había establecido en el artículo 4 del texto aprobado en $1947^{10}$.

Frente a esta crisis del sistema de seguridad interamericana, cabe preguntarse qué papel podría cumplir el tratado de Tlatelolco en esta era nuclear, cuando un número significativo de países de la región, han accedido ya a este tipo de tecnología. El problema no es simple, pues el Tratado de Tlatelolco posee un régimen jurídico completo, pues pretende reglamentar las relaciones tanto entre países de la región no dotados de armas nucleares, como aquellas entre países regionales y potencias intra y extracontinentales pero poseedoras del poder nuclear.

Como elemento adicional a la problemática que acabamos de esbozar es necesario señalar que el continente americano ha penetrado desde un comienzo a través de uno de sus "animales racionales" a la "selva nuclear"11. En efecto, los Estados Unidos hasta 1949 monopolizan el poder nuclear, situación que los lleva a presentar un primer plan (plan Baruch en junio de 1946), tendiente a crear una Agencia Internacional, la que ejercería un control sobre materiales y actividades atómicas potencialmente peligrosas para la seguridad mundial, pero que persigue en los hechos, evitar que nuevos Estados se dotarán de un arsenal nuclear independiente ${ }^{12}$. Sabemos el resultado de estas últimas intenciones ante el problema de lo que se ha conocido como el "enésimo país".

Sin embargo, es un hecho que los Estados Unidos han asumido por múltiples razones una política tendiente a limitar la proliferación de armas nucleares. Es así, y refiriéndonos por el momento solamente al

${ }^{9}$ En efecto el nuevo artículo 2 si bien reafirma la existencia de mecanismos regionales para la solución de controversias, no priva a los países miembros de la OEA a recurrir al sistema de solución de controversias contemplado en la Carta de las Naciones Unidas.

vi Tal fue la posición de México que deseaba restringir al máximo la zona de seguridad persiguiendo disminuir los riesgos de que un Estado parte fuese atacado. Tal posición no fue adoptada pues sólo se restringió la zona en cuestión. Véase la comparación de ambos artículos en el estudio de Orrego (F.). "El sistema interamericano de seguridad colectiva", en la obra Antecedentes, balance y perspectivas ..., op. cit., p. 131.

${ }^{11}$ Hemos adoptado una terminología utilizada por Gustavo Lagos en su artículo, "La Fábula de los animales de Helsinki y de Salt $\mathrm{II}$ ", en la obra "La détente y las crisis planetarias", Santiago, Instituto de Estudios Internacionales, Serie de Publicaciones especiales $\mathrm{N}^{\circ} 16,1976,230$ págs., pp. 18-36.

${ }^{12}$ Cr. Castañeda (J.), La no proliferación de las armas nucleares en el orden universal, México, El Colegio de México, $196 \%,+7 /$ págs., p. $\%$ 
plano universal, que en agosto de 1967 los Estados Unidos y la Unión Soviética presentaron ante el Comité de Desarme un proyecto conjunto de tratado de no proliferación de armas nucleares. Si bien este proyecto sufrió modificaciones ${ }^{13}$, fue aprobado por una amplia mayoría de Estados. Sin embargo hasta la fecha no son parte de él cuatro países de América Latina: Argentina, Brasil, Cuba y Chile. Habría que agregar además aquellos otros Estados de la región que no han procedido todavía a su ratificación ${ }^{14}$. Estos últimos antecedentes permiten señalar que no ha sido del toda exitosa la persuasión norteamericana en el sentido de que países de la región, sobre todo aquellos más cercanos al "dintel nuclear", acepten el status quo nuclear universal ${ }^{15}$.

La situación no es diametralmente diferente a aquella que ocurre en el plano regional, particularmente frente al Tratado de Tlatelolco. Los cuatro países que no son parte del TNP aparecen en situación especial frente al instrumento que persigue desnuclearizar la región. No es por simple coincidencia que la duodécima segunda recomendación del informe Linowitz hace hincapié en el sentido de que Estados Unidos debe alentar nuevas adhesiones al Tratado sobre Prohibición de Armas Nucleares en América Latina ${ }^{16}$.

Esta recomendación ha sido retomada oficialmente por el presidente Carter, quien por medio del secretario de estado Sr. Vance ha señalado que en la concesión de ayuda económica se deberá considerar, entre otras cosas, el problema de la proliferación nuclear. Tal política ha llevado a un enfriamiento de las relaciones entre Estados Unidos, Brasil y Argentina. Estos dos países han resistido hasta la fecha las fuertes presiones norteamericanas, y un sentimiento "nacionalista" ha alcanzado a diseñarse aun en publicaciones académicas latinoamericanas ${ }^{17}$.

${ }^{13}$ Sobre las modificaciones de que fue objeto, véase Castañeda (J.), La no proliferación de las armas nucleares...,op. crt.

${ }^{1+}$ Dichos países aparecen citados en el artículo de Fischer (G.). "La conferénce des parties chargées de l'éxamen du traité sur la non-prolifération des armes nucleaires", A.F.D.I., 1975, Pp. 9-43.

${ }^{15}$ Subre el TNP y sus actuales proyecciones, véase el trabajo de Alessandri, Armanet y Orrego, "El tratado de no proliferación y las nuevas alternativas de la política nuciear". en Orrego (F.), y Armanet (P.), Política Nuclear, Santiago Editorial Universitaria, 1979. 348 págs., pp. $270-291$.

${ }_{16}$ Véase una traducción de este informe y de sus recomendaciones en Vargas (R.), Estados Unidos y América Latina bajo la presidencia de Garter ..., op. cit., pp. 100-104.

${ }^{17}$ A modo de ejemplo se puede citar la consagración casi completa del $N^{\circ} 42$ de la Revista Estrategia a políticas latinoamericanas en materia nuclear. Véase igualmente el artículo de Sábato (J.). "El Plan nuclear brasilero y la Bomba Atómica", en Estudios Internacionales $N^{*} 41$, enero-marzo 1978, pp. 73-82. 
Sin embargo, cabe preguntarse sı esta oposición de los Estados Unidos a una política nuclear independiente de ciertos países latinoamericanos corresponde exclusivamente a concepciones humanitarias o éticas. Es un hecho que frente a un aumento significativo y a la incertidumbre de los suministros petroleros se han estimulado planes de gran envergadura para la construcción de modernas instalaciones de energía nuclear tendientes a "aumentar la parte de la capacidad generadora de electricidad de Occidente del 2 hasta el $15 \%$ en $1985^{\prime \prime 18}$. Tal situación ha acelerado una nueva industria, "la industria internacional de reactores" con las consiguientes consecuencias económicas y políticas tanto entre los países exportadores como importadores. En este contexto deben situarse el acuerdo nuclear firmado en junio de 1975 entre Brasil y la República Federal de Alemania y la licitación nuclear a que ha llamado Argentina.

La diversificación de proveedores en materia de tecnología nuclear, sumada a una creciente diversificación ocurrida en el mercado de armamentos convencionales ${ }^{19}$, puede conducir, y con bastante probabilidad, a lo que el canciller del Brasil llamaba "interdependencia horizontal" entre países de la región y potencias extracontinentales.

Una situación semejante a la descrita tendrá que producir obligatoriamente quiebres y/o redefiniciones de antiguos esquemas interamericanos, incluyendo aquellos referente a sistemas de seguridad regional. Esta afirmación no excluye la posibilidad que se desarrollen "actitudes complementarias ${ }^{220}$, tanto a nivel interno nacional, las llamadas doctrinas de la seguridad nacional por ejemplo, como en las relaciones externas entre países latinoamericanos a través de alianzas más o menos institucionalizadas para defender intereses comunes permanentes o fundamentales.

\section{LA GÉNESIS Y REALIDAD DIVERSA DEL SISTEMA DE SEGURIDAD clásigo y del Tratado del Tlatelolgo}

El sistema de seguridad interamericano se origina en el contexto internacional que precede a la Segunda Guerra Mundial y recibe gran parte de su aplicación durante el período de la guerra fría. Tanto en su origen como en su aplicación, el sistema supone una alineación rígida con el líder del bloque, los Estados Unidos.

\footnotetext{
${ }^{18} \mathrm{Cf}$. Gall (N.), Energía atómica para el Brasil ..., op. cit.. p. 83.

${ }^{19}$ Cf. Portales (C.), y Varas (A), Carrera Armamentista en América del Sur, Revista Mensaje $N^{\circ}$ 276, enero-febrero 1979, pp. 53-59.

${ }^{20} \mathrm{Cf}$. Orrego (F.), El sistema interamericano de seguridad ..., op. cit.. p. 124.
} 
El objetivo general del sistema de seguridad interamericano fue preservar "la paz de América", aun cuando esta noción haya variado de contenido entre 1936, fecha en que se suscribe la Convención sobre Mantenimiento, Afianzamiento y Restablecimiento de la $\mathrm{Paz}^{21}$, y 1975 , fecha en que se reforma uno de sus pilares, el tiar. Pero este objetivo de tipo general se especifica con el tiempo a través de un proceso tendiente a determinar cuáles son los bienes protegidos que preservará el sistema. En 1940, en la Segunda Reunión de Consulta ocurrida en La Habana, se establecen como bienes protegidos la integridad o inviolabilidad territorial y la soberanía o independencia política de un Estado americano. Frente a cualquier hecho, denominado genéricamente como agresión, destinado a desconocer o menoscabar los valores ya determinados se prevé un medio de acción, la consulta.

Sin embargo, si en un comienzo la agresión podría estar constituida por las posibles derivaciones de la guerra europea (una agresión extracontinental), posteriormente en el Acta de Chapultepec se complementa el sistema al incluirse la hipótesis de la agresión intracontinental. No obstante lo acertado de esta última afirmación cabe señalar que el sistema funciona en forma" dependiente de los intereses circunstanciales de los Estados Unidos. Es así como durante la guerra de Corea, la Cuarta Reunión de Consulta ạdemás de apoyar "la acción de Naciones Unidas", recomienda a los países de la región "incrementar aquellos de sus recursos y reforzar aquellas de sus fuerzas armadas en condiciones tales que puedan estar prontamente disponibles para la defensa del Continente....222.

Ahora bien, sería necesario precisar esta asociación de los países de la región en la defensa del continente. Según algunos autores ${ }^{23}$, las razones por las cuales los Estados Unidos han asociado a los países de la región en la defensa del continente han sido primordialmente razones de orden político y no militares o estratégicos. La necesidad de combatir en conjunto la subversión comunista ha sido el elemento catalizador del Sistema ${ }^{24}$; la cooperación frente a una posible agresión armada extracontinental ha descansado exclusivamente sobre los Estados Unidos.

${ }^{21}$ Sobre esta reunión, véase el estudio de Yepes (J.M.), La conception Américaine de la Paix et la Conférence de Buenos Aires, R.G.D.I.P., 1937, pp. 330-368.

2.2 Texto citado por Connell-Smith (G.), El sistema interamericano. Méxicn. Fondo de Cultura Económica, 1971, 487 págs., p. 262.

${ }_{23}$ Entre ellos el propio Conneli-Smith, op. cit., p. 264.

${ }^{2+}$ Orrego (F.), escribe a este propósito... "El hecho concreto es que, durante este periodo de guerra fria, representado principalmente por la situación cubana, el sistema de seguridad colectiva evolucionó hacia la regulación de las nuevas formas de guerra no convencional" ..., Cf. El sistema interamericano de seguridad ...op. cit.. p. 118. 
Sabemos que los cambios políticos ocurridos con posterioridad en diferentes países de América Latina y la crisis interna que conoció los Estados Unidos, ambos hechos enmarcados en un escenario de la détente, determinaron reflexiones y también revisiones del Sistema Interamericano de Seguridad. Fue así como el 15 de abril de 1973 la Asamblea General de la oEA aprobó una resolución que sostiene que la pluralidad de ideologías es un supuesto de la solidaridad regional. Tal resolución constituía el término de vigencia del Acta de Punta del Este de 1962, donde se declaró la incompatibilidad entre el marxismo-leninismo y el sistema interamericano.

Todos estos antecedentes llevaron a la reforma del TIAR, modificaciones que tienden a introducir una mayor participación del Sistema de Naciones Unidas en la seguridad regional. Es decir, sin rechazar la existencia de un esquema interamericano de seguridad, se pretende globalizarlo, neutralizando las importantes influencias políticas de los Estados Unidos e imposibilitando futuras asimilaciones entre subversión, intervención y al concepto de agresión redefinido.

Cabe preguntarse entonces ¿cuál es el futuro del sistema interamericano de seguridad? Para responder a esta interrogante sería conveniente comenzar por señalar aquellos hechos que escaparían por su naturaleza al Sistema, dejando para un análisis posterior aquellos sobre los cuales un esquema como el actual sigue aún vigente.

En primer lugar, no se podría incluir en el ámbito de aplicación futura del sistema, aquellas agresiones que no implican utilización de la fuerza y que se conocen como agresiones indirectas (subversión, intervención, etc.). Sobre el particular existe hoy en día mayor conciencia en los Estados Unidos sobre todo después de experiencias negativas regionales y universales. Así en la primera recomendación del informe Linowitz se insta a la nueva administración a comprometerse a no llevar a cabo ninguna intervención militar unilateral o intervención encubierta en los asuntos internos de los países de la región.

En segundo lugar, la reforma del TIAR termina con la facultad amplísima que poseía el Organo de Consulta para determinar los actos de agresión. Se sabe que el protocolo de San José de Costa Rica adopta el criterio objetivista que caracteriza la definición internacional de la agresión formulada por la Asamblea General de Naciones Unidas ${ }^{25}$. En el futuro dificilmente podrá desnaturalizarse el sistema a través de calificaciones liberales del Organo de Consulta.

${ }^{25}$ Véase nuestro estudio "Los elementos objetivos $y$ subjetivos en la definición internacional de la agresión". Revista Estudios Internacionales, $N^{\circ} 43$, julio-septiembre 1978. pp. 90-107. 
El sistema interamericano de seguridad permanece vigente para los actos de agresión (ataques armados) de origen continental o extracontinental y para aquellos otros definidos casuísticamente pero que se refieren a hipótesis de agresiones directas (invasión de territorios, bombardeos, bloqueos, etc.).

Sin embargo esas hipótesis de aplicación del sistema son como lo demuestra la experiencia; las menos frecuentes; además se ha recurrido recientemente en controversias entre países de América del Sur a los buenos oficios y a la mediación de entidades extracontinentales.

Junto a estos antecedentes cabe señalar el condicionamiento cada vez más extenso que ha efectuado el Congreso norteamericano de la ayuda militar y venta de armamentos en relación al respeto de los derechos humanos por los países receptores de la región ${ }^{26}$.

Es decir, tanto desde la perspectiva latinoamericana como de aquella de los Estados Unidos existe una pérdida de credibilidad con respecto a la utilidad del sistema de seguridad interamericano; existe también, sobre todo por parte de los Estados Unidos un desinterés en comprometerse en forma global con América Latina, pretendiendo distinguir las peculiaridades de cada país iberoamericano en la formulación de la política exterior norteamericana ${ }^{27}$.

El origen y la situación actual del Tratado de Tlatelolco es distinta a un esquema como el que acabamos de analizar. La idea de desnuclearizar América Latina se gesta en un contexto internacional distinto, con actores y motivaciones diferentes.

El 29 de abril de 1963, cinco Jefes de Estados (de Bolivia, Brasil, Chile, Ecuador.y México) preocupados por la situación internacional que favorecía la proliferación nuclear, y considerando la tradición pacifista de la región, proponen desnuclearizar América Latina lo que contribuiría a la adopción de un instrumento universal.

Esta declaración se efectuaba seis años después del fracaso del plan Rapacki sobre desatomización de Europa central $^{28}$, y cuatro años antes de que Estados Unidos y la Unión Soviética presentaran al Comíté de Desarme un proyecto conjunto de tratado sobre no proliferación de armas nucleares.

\footnotetext{
${ }^{26}$ Véanse como ejemplo las enmiendas propuestas por los Senadores Church y Kennedy al "International Security Asistance and Arms Export Control Act".

${ }_{27}$ Tales ideas aparecen en el discurso pronunciado por el presidente Carter ante la OEA, 14 de abril de 1976.

${ }^{28}$ Plan presentado por primera vez a las Naciones Unidas en 1957, por el ministro de Kelaciones Exteriores de Polonia; dicho plan abarcaba Polonia. Checoslovaquia, la República Federal y la República Democrática de Alemania.
} 
La Asamblea General de Naciones Unidas en su decimoctavo período de sesiones adoptaba la resolución 1911 (xvin) ${ }^{29}$, en la cual además de aceptar con satisfacción la iniciativa presidencial latinoamericana, expresaba la esperanza de que los países de la región iniciaran los estudios necesarios para implementar los propósitos contenidos en aquélla, otorgándole a través del Secretario General la colaboración técnica de la Organización.

La resolución en cuestión señalaba además, y ello es importante, que una vez concluido un acuerdo regional con tales objetivos, todos los Estados, en especial las potencias nucleares, deberían prestarle su plena cooperación.

Los anhelos contenidos en la resolución de la Asamblea General se materializaron rápidamente, pues al año siguiente tuvo lugar en México la reunión preliminar sobre la Desnuclearización de América Latina. En dicha reunión se creó una comisión preparatoria, a la cual se le encargó que preparara un anteproyecto de tratado multilateral con el objetivo de desnuclearizar la región.

La elaboración del tratado se realizó en cuatro períodos de sesiones, desde el año 1965 a 1967. Es interesante recalcar el progresivo aumento del número de Estados observadores continentales y extracontinentales que va de un período a otro.

Primer período de Sesiones 15 al 22 de marzo de 1965

Segundo período de Sesiones 23 de agosto al 2 de septiembre de 1965

Tercer período de Sesiones 19 de abril al 4 de mayo de 1966
Observadores:

Guatemala, Holanda y Yugoslavia

Observadores:

Canadá, Dinamarca, Estados Unidos. Inglaterra, Italia, Japón, Noruega, Holanda, Suecia y Yugoslavia

Observadores:

Austria, Canadá Dinamarca, Estados Unidos, Francia, Inglaterra, India, Italia, Japón, Noruega, Polonia, República Arabe Unida, República Federal de Alemania, Suecia y Yugoslavia

\footnotetext{
${ }^{29}$ Resolución adoptada el 27 de noviembre de 1963.
} 
Cuarto período de Sesiones 30 de agosto de 1966 al 14 de febrero de $1967^{*}$
Observadores:

Austria, Bélgica, Canadá, Dinamarca, Estados Unidos, Finlandia, Francia, Ghana, Inglaterra, India, Israel, Italia, Japón, Noruega, Holanda, Polonia, República Arabe Unida, República de China, República Federal de Alemania, Rumania, Suecia y Yugoslavia

* El cuarto período de Sesiones constó de dos Sesiones; la primera, el 30 de agosto de 1966, la segunda, el 31 de enero de 1967 al 14 de febrero del mismo año.

De este cuadro algunos aspectos interesantes pueden desprenderse o señalarse: en el primer período dejando a un lado el caso de Guatemala, nos encontramos con dos observadores distintos; Holanda, país extracontinental pero con territorios en la región bajo su responsabilidad en aquella época, y Yugoslavia, país extracontinental y fundador del movimiento de los no-alineados. El segundo aspecto que cabe recalcar es la no presencia de la Unión Soviética en los cuatro períodos de Sesiones. La presencia de dos países socialistas, Polonia y Rumania, se justifica por razones diversas: el primero, por ser el país que presentara por primera vez un plan de desnuclearización regional; el segundo, por su posición independiente en materia internacional. El tercer aspecto a señalar es que la inasistencia de la República Popular China se debe a que dicho país ligaba los esfuerzos latinoamericanos a la resolución de la Asamblea General de Naciones Unidas, organización que había conculcado los legítimos derechos de la potencia asiática 30

Por último cabe mencionar el hecho de que uno de los Estados extracontinentales responsable internacionalmente en aquella época por territorios en América, Holanda, solicitó durante el cuarto período de Sesiones, participar en igualdad de derechos con los Estados miembros. Tal solicitud fue retirada ante el acuerdo de que los Estados extracontinentales que se encontraban en condiciones análogas no serían Partes Contratantes en el tratado que se estaba elaborando.

El tratado sobre proscripción de las armas nucleares en América Latina posee una primera característica que es el ser un instrumento exclusi-

30 El 8 de agosto de 1966 la República Popular de China a través de su embajador en El Cairo comunicó su posición al Comité Negociador de la Comisión Preparatoria para la desnuclearización de América Latina. Al respecto véanse los informes en García Robles (A)., El Tratado de Tlatelolco, México, El Colegio de México, 1967, 339 págs., pp. 228-231. 
vamente latinoamericano a diferencia de otros acuerdos regionales en materia de seguridad.

Constituye igualmente una etapa en la larga y difícil búsqueda del desarme mundial, estableciendo una zona desnuclearizada del planeta. Quizás, como lo señala Daniel Colard, más que una medida de desarme el tratado de Tlatelolco constituye una medida de "non-armement"

El instrumento en cuestión parte de un presupuesto básico en estrecha relación con los objetivos primordiales de este trabajo al prever que el establecimiento de zonas militarmente desnuclearizadas está íntimamente vinculado al mantenimiento de la paz y la seguridad en la región. Además la existencia de armas nucleares en cualquier país de América Latina lo convertiría en blanco de eventuales amenazas o ataques nucleares, situación que tendría incidencia en la carrera armamentista, esta vez nuclear, con la consiguiente desviación de los recursos financieros nacionales.

El último presupuesto en que se basa el Tratado de Tlatelolco, se refiere a la necesidad de que la energía nuclear sea usada en la región exclusivamente para fines pacíficos, para lo cual los países latinoamericanos deben utilizar su derecho de acceder en forma equitativa a esta nueva fuente de en ergía con el objeto de acelerar el desarrollo económico y social de sus nacionales.

La parte dispositiva puede ser analizada brevemente bajo tres ángulos: el régimen de las obligaciones, el sistema de control y por último los aspectos institucionales.

El primer ángulo posee un aspecto positivo y otro negativo. Las Partes Contratantes se comprometen a "utilizar exclusivamente con fines pacíficos el material y las instalaciones nucleares sometidos a su jurisdicción" ${ }^{\prime 32}$; por otra parte, los Estados se comprometen a prohibir e impedir en cualquier forma que en sus respectivos territorios se realicen ensayos, usos, fabricación, producción, adquisición de toda arma nuclear. Tal prohibición alcanza al recibo, almacenamiento, instalación, emplazamiento o cualquier forma de posesión de armas nucleares.

Complementa este conjunto de obligaciones la definición que entrega el tratado de armas nucleares. El artículo 5 dispone que se entiende por arma nuclear "todo artefacto que sea susceptible de liberar energía nuclear en forma no controlada y que tenga un conjunto de características propias del empleo con fines bélicos". Esta definición que fue objeto de laboriosas deliberaciones, tuvo su origen en aquella contenida en el Protocolo sobre Control de Armamentos del Tratado de la Unión Occidental

\footnotetext{
${ }^{31}$ Cf. "Le désarmement", París, Armand Colin, 1972, 125 págs., p. 46.

32 Véase al respecto el artículo 17 del Tratado.
} 
Europea (23 de octubre de 1954), por el cual la República Federal de Alemania se comprometió a no fabricar en su territorio armas atómicas biológicas o químicas. La característica del texto es que es objetivo, omitiéndose toda referencia a los fines o intenciones en cuanto a su utilización; distingue al mismo tiempo entre aquellos instrumentos de transporte o propulsión de un arma nuclear que fuesen separables de la misma y aquellos que fuesen parte indivisible de ella.

El segundo aspecto que resulta conveniente analizar se refiere al sistema de control. Este último es doble, diferenciándose del tratado sobre no proliferación de las armas nucleares. Además de un sistema de salvaguardias mediante acuerdos, multilaterales o bilaterales, concluidos con el Organismo Internacional de Energía Atómica, se prevé el control por parte de un organismo ad hoc, el organismo para la Proscripción de las Ármas Nucleares en la América Latina (OPANAL), el cual, particularmente a través de dos órganos, puede realizar inspecciones o requerir informaciones respecto de cualquier hecho o circunstancia relacionada con el cumplimiento del Tratado.

Las razones de este doble control se deben a que en el Tratado de Tlatelolco, no sólo está prohibido el ensayo, uso, fabricación o adquisición de armas nucleares, sino también el "recibo, almacenamiento, instalación, emplazamiento o cualquier forma de posesión de toda arma nuclear, directa o indirectamente, por sí mismas, por mandato a terceros o de cualquier otro modo". El tratado latinoamericano es en este punto más amplio que el instrumento universal pues este último no prohíbe la instalación o emplazamiento de armas nucleares en el territorio de un Estado no nuclear si la potencia nuclear conserva su control como sucede con algunas bases nucleares americanas ${ }^{33}$. Si bien hasta la fecha se ha insistido en que basta ser parte del Tratado de Tlatelolco para concluir los acuerdos de salvaguardias y asegurarse, por ende, la cooperación científica, tecnológica, financiera, económica e industrial en materia de energía nuclear, existe conciencia más o menos generalizada de que un Organismo a nivel regional debería coordinar, asesorar y ayudar a los países del continente en la planeación y realización de sus proyectos energéticos. El Secretario General de o panal, a raíz del $\mathrm{X}$ aniversario del Tratado, aniversario que fue celebrado durante la Conferencia General Extraordinaria, 1977, expresó con claridad la nueva misión que debería corresponderle a OpANAL: “...su misión no ha de ser sólo la de controlar la aplicación estricta de la proscripción de armas nucleares prevista en el Tratado de Tlatelolco, sino que también ha de incluir el elemento

${ }^{33}$ Cf. Castañeda (J)., La no proliferación de las armas nucleares. .. op. cit. p. 23. 
positivo, resultante de ser el organismo encargado de programar y coordinar regionalmente, de acuerdo a la voluntad de los Estados latinoamericanos, el uso pacífico de la energía nuclear en el continente..."34.

En cuanto a los aspectos institucionales, último punto que pretendemos analizar, es necesario señalar que a fin de asegurar el cumplimiento de las obligaciones impuestas por el Tratado se ha creado en él mismo un organismo internacional que ya hemos individualizado (opanal). Tal organismo se compone de tres órganos principales: la Conferencia General, el Consejo y la Secretaría.

Junto al Tratado existen dos protocolos adicionales. El primero se refiere a aquellos Estados que de jure, o de facto, tienen territorios bajo su responsabilidad internacional dentro de los límites de la zona geográfica establecida en el tratado ${ }^{35}$. A dichos países se les aplica, una vez ratificado el protocolo, el estatuto de desnuclearización para fines bélicos definido en el tratado (artículos 1, 3, 5 y 13). No se les aplica el sistema de control y la suscripción de dicho protocolo puede ser objeto de reservas, institución prohibida para los Estados partes.

El protocolo II, abierto a la firma de países nucleares, dispone sólo dos obligaciones: la primera, una obligación de comportamiento, el "no contribuir en forma alguna a que, en los territorios a los que se refiere el Tratado de conformidad con el artículo 4, sẹan practicados actos que entrañen una violación de las obligaciones enunciadas en el artículo 1 del Tratado"; la segunda, que dice relación con el respeto debido al estatuto de las Partes en el tratado, consiste simplemente en "no emplear armas nucleares y no amenazar con su empleo contra las Partes Contratantes...".

Todos estos antecedentes nos han permitido estudiar el origen y los principales objetivos del Tratado de Tlatelolco. Enseguida nos corresponde observar su actual realidad, para lo cual se inserta el siguiente cuadro:

\section{Tratado de Tlatelolco}

Estados signatarios

Estados no signatarios

Estados ratificantes con dispensas

Estados ratificantes sin dispensas

Estado no ratificante

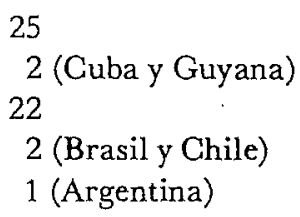

1 (Argentina)

${ }^{34}$ Cf. el discurso del Secretario General en Gros Espiell (H)., El Tratado de Tlatelolco. Diez años de Aplicación. Publicaciones del o Panal, Serie Estudios y Monografias $\mathrm{N}^{\circ} 5$, 1978, 113 págs., p. 21.

${ }^{35}$ Véase el artículo 4. 


\section{Protocolo Adicional I}

$\begin{array}{ll}\text { Estados signatarios y ratificantes } & \text { Inglaterra y Holanda } \\ \text { Estados signatarios } & \text { Estados Unidos y Francia }\end{array}$

Protocolo Adicioanl II

Estados signatarios y ratificantes

Estado signatario
Inglaterra, Estados Unidos, República Popular de China y

Francia

Unión Soviética

Los comentarios que efectuaremos respecto de este cuadro nos introducen ya en la segunda y tercera parte de este estudio. Tal manera de proceder responde a un interés de realizar un análisis sistemático del Tratado de Tlatelolco tanto al interior del continente como en su inserción en el actual contexto internacional.

\section{El Tratado de Tlatelolco o el eqứvoco en las concepgiones}

En el continente americano podemos distinguir cuatro grandes posiciones o concepciones con referencia al Tratado de Tlatelolco: los países no signatarios; los Estados signatarios y ratificantes; los países en situación especial, y por último la posición de los Estados Unidos.

En primer lugar aparece necesario situar la negativa de Cuba y Guyana a firmar el tratado, pues son los únicos países del continente que se encuentran en tal posición. El Gobierno de Cuba no designó representante en el primer período de sesiones (marzo de 1965), fundando su actitud en la posesión ilegal por los Estados Unidos de la base naval de Guantánamo sumada a la política agresiva de Norteamérica, única potencia hemisférica dotada de armas nucleares en contra de Cuba y de otros países de América Latina.

La comunicación, fechada el $1^{\circ}$ de diciembre de $1965^{36}$, hace referencia también a la intervención de los Estados Unidos en República Dominicana y a la creciente escalada en Vietnam.

Posteriormente Cuba reafirmó su posición ante el Consejo de Seguridad, reunido en Panamá en 1973. En aquella ocasión dicho país expresó

${ }^{36}$ Cf. texto en García Robles (A)., El tratado de Tlatelolco... op. cit., pp. 165-166. 
que mientras el tratado no abarcara a la única potencia nuclear del hemisferio, Cuba se inhibiría de participar en aquel instrumento.

Frente a tales declaraciones oficiales que no han sido modificadas hasta la fecha, caben algunos comentarios. La posición de Cuba frente al Tratado de Tlatelolco es congruente con su posición en relación al tratado sobre la no proliferación de las armas nucleares (TNP). Como se sabe, Cuba fue uno de los cuatro países que votaron en contra del instrumento universal ${ }^{37}$.

El Gobierno de Cuba aun cuando ve con simpatías los esfuerzos para hacer de América Latina una región desnuclearizada supedita su participación a tres condiciones: término de la presencia norteamericana en Guantánamo, término de la política agresiva de los Estados Unidos y desnuclearización real del hemisferio.

No nos referiremos a las dos primeras condiciones pues ellas son esencialmente temporales e inciden en la décima recomendación del informe $\mathrm{Li}$ nowitz, tendiente a reabrir en forma gradual y recíproca el proceso de normalización de relaciones entre Estados Unidos y Cuba. Es decir, ellas forman parte del contencioso aún pendiente y sujeto a negociaciones.

La tercera condición impuesta por Cuba debe, a nuestro juicio, ser precisada, pues ella es equívoca. En efecto, tal condición podría tener dos significados: el primero, Cuba al momento de expresarla lo hacía ante la negativa de los Estados Unidos de firmar el protocolo adicional I, actitud que le permitía "nuclearizar" las Islas Vírgenes, Puerto Rico, Guantánamo y la Zona del Canal; el segundo significado, es que Cuba cree en un desarme nuciear generalizado, vertical y horizontal, de ahí su negativa a formar parte del TNP. Cuba vería el Tratado de Tlatelolco como un TNP regional, imponiendo obligaciones sólo a los Estados no nucleares y dejando libre la carrera armamentista nuclear.

A pesar de toda esta problemática subyacente, existen antecedentes recientes en el sentido de que Cuba cuenta en la actualidad con un reactor de investigación y que habría firmado un convenio con la Unión Soviética para la provisión de una central de $440 \mathrm{MV}$ a uranio enriquecido con opción a una segunda del mismo tipo ${ }^{38}$.

La situación de Guyana es distinta, pues su caso cae en la hipótesis contemplada en el artículo 25 párrafo 2, del tratado, disposición según la

37 Votaron con Cuba, Albania, Tanzania y Zambia.

${ }^{38}$ Cf. Sábato (J.) y y Frydman (R.). La energía nuclear en América Latina en Revista Estrategia $\mathrm{N}^{\circ}$ 42, Págs. 54-62, p. 60. Sin embargo esta información aparece contradicha por un comentario aparecido en el diario El Mercurio de fecha 18 de marzo de 1978, en el cual se consigna la idea de que la Unión Soviética habría descartado la idea de instalar en territorio cubano una central de potencia. 
cual no se admitirá la admisión de una entidad política cuyo território esté sujeto total o parcialmente y con anterioridad a la fecha de la apertura a la firma del tratado, a litigio o reclamación.

Como se sabe dentro del sistema interamericano y en especial después de la suscripción del Acta de Washington durante la Primera Conferencia Interamericana Extraordinaria, se resolvió que el Consejo de la Organización de Estados Americanos, no tomaría ninguna decisión sobre solicitud de admisión presentada por una entidad política cuyo territorio esté sujeto, total o parcialmente a litigio o reclamación, mientras no se haya puesto fin a la controversia mediante procedimiento pacífico ${ }^{39}$.

Dicho criterio fue seguido en Tlatelolco lo que impidió a Guyana, que posee una antigua controversia con Venezuela ${ }^{40}$, a suscribir el instrumento regional. Sin embargo en repetidas ocasiones Guyana ha manifestado su interés por adherir al tratado ${ }^{41}$; las negociaciones se han efectuado entre una Comisión de Buenos Oficios de opanal y el Gobierno de Georgetown. Sin embargo existe al respecto una opinión generalizada de que la situación de Guyana debe ser resuelta con el acuerdo y la voluntad unánime de todos los Estados latinoamericanos.

La segunda posición, constituída por aquellos Estados signatarios y ratificantes (22 Estados), concibe el Tratado de Tlatelolco como un nuevo instrumento de seguridad regional, pues responde a una de las ideas básicas del concepto de "seguridad", cual es el establecimiento de una zona libre de peligro o de riesgo nuclear. Tal idea matriz apareció ya con nitidez en la declaración presidencial conjunta del 29 de abril de 1963, y ha sido reafirmada recientemente en la reunión de los Presidentes de Colombia, Costa Rica, Jamaica, Panamá y Venezuela, celebrada en agosto de 1977.

"La desnuclearización militar de la América Latina - dice por lo demás el propio preámbulo- entendiendo por tal el compromiso internacionalmente contraído... de mantener sus territorios libres para siempre de armas nucleares, constituirá una medida que evite a sus pueblos el derroche en armamento nuclear, de sus limitados recursos, y que los proteja contra eventual es ataques nucleares a sus territorios...".

Pero además de esta idea de establecer una zona libre de peligro o de riesgo, los Estados Partes en el tratado se imponen recíprocamente una

\footnotetext{
${ }^{39}$ Véase el artículo 8 de la carta de la Organización de Estados Americanos después de la reforma efectuada en el Protocolo de Buenos Aires.

${ }^{40}$ Se trata de la reclamación de V́enezuela sobre la Guyana Esequiba.

41 En la reunión del Consejo de Seguridad efectuada en Panamá en marzo de 1973, Guyana reafirmó el deseo de ser Parte Contratante, siendo apoyada por Jamaica. Véase Gros (H)., En torno al tratado de Tlateloico y la Proscripción de Armạs Nucleares en América Latina, Publicaciones del opanal, Serie: Estudios y Monografías, Nº 1, 1973, 61 pág., p. 30.
} 
serie de obligaciones, creando un sistema decuado de control, interno, a través del Organismo para la proscripción de las Armas Nucleares en la América Latina; externo a través del Organismo Internacional de Energía Atómica.

Ahora bien, si a pesar del control se produjese un incumplimiento constitutivo de violación de las obligaciones impuestas por el tratado que ponga o pusiese en peligro la paz y la seguridad, la Conferencia General informará simultáneamente al sistema de Naciones Unidas y a la Organización de Estados Americanos.

Un sistema de seguridad sería ineficaz si los actores perturbadores de la paz y seguridad hemisférica, es decir, las potencias dotadas con armas nucleares, pudieran desconocer el estatuto de desnuclearización de la región o amenazaren emplear armas nucleares contra países de la región. Los protocolos adicionales I y II, responden a la noción de mecanismos de garantía, semejantes a las declaraciones efectuadas por la uRss, Inglaterra y Estados Unidos ante el Consejo de Seguridad en el seno del TN $\mathrm{P}^{42}$, aun cuando el valor jurídico de los primeros es mayor que en el segundo caso ${ }^{43}$.

La tercera posición está constituida por los países que se encuentran en situación especial en referencia al Tratado de Tlatelolco, es decir, Argentina, Brasil y Chile. Estos tres países poseen planes sobre energía nuclear de desigual desarrollo.

En lo que se refiere a la República Argentina si bien no formaba parte de la declaración.conjunta de Presidentes de fecha 29 de abril de 1963 , adhiere a ella por nota del 11 de julio del mismo año, señalando, eso sí, que debía lograrse el concierto previo y unánime de los Estados latinoamericanos sobre los principios y características que tendría el futuro

\footnotetext{
${ }^{+2}$ Como se sabe, durante la elaboración del TNP uno de las mayores problemas que se presentó fue aquel de las garantías, ya que había que estudiar la situación de los Estados que renunciaban a la fabricación de armas nucleares en cuanto a su protección futura frente a una potencia nuclear que pudiera amenazarlos. Un primer ejemplo de garantía lo ofreció el primer ministro Kósyguin, quien el $1^{\circ}$ de febrero de 1966, dirigiéndose al Comité de Desarme, manifestó que las potencias nucleares podrían asumir el compromiso de no usar armas nucleares contra las naciones no nucleares que adhieran el tratado y que no dispongan de armas nucleares en su propio territorio. Esta fórmula conocida como fórmula Kosyguin, no fue aceptada por los Estados Unidos porque le habría significado que algunos de sus aliados República Federal de Alemania, España y Turquía, que poseían en la época bases nucleares norteamericanas, no quedarían protegidos por la garantía. La diferencia de criterios no pudo encontrar solución al interior del tratado por lo que fue necesario efectuar aquellas declaraciones unilaterales de idéntico contenido. Cf. Castañeda (J.), La no proliferación de las armas...,op.ctt., pp. 36-46.

${ }^{43}$ Los protocolos adicionales I y II forman parte integrante del Tratado de Tlatelolco y poseen obligaciones más amplias que aquellas contenidas originariamente en la fórmula Kosyguin.
} 
tratado, y estimaba que el lugar adecuado para discutirlo era la Organización de Estados Americanos.

Posteriormente participa en la Reunión preliminar y concurre a todos los períodos de sesiones. Firma el tratado el 27 de septiembre de 1967, o sea, después de siete meses de haber quedado abierto para ello y cuando todos los otros Estados asistentes, menos uno, lo habían firmado entre abril y junio de ese año.

Sin embargo, y ello es importante señalarlo y transcribirlo, Argentina firma el tratado con la siguiente declaración:

"El Gobierno de la República Argentina, al firmar el Tratado para la Proscripción de las Armas Nucleares en la América Latina, de conformidad al artículo veintiocho inciso primero, desea expresar su satisfacción por la inclusión en el instrumento de ciáusulas que preservan el desarrollo pacífico de la energía nuclear y, entre ellas, del artículo dieciocho que reconoce el derecho de las partes contratarites a realizar, y por sus propios medios o en asociación con terceros, explosiones de dispositivos nucleares con fines pacíficos, inclusive explosiones que presupongan artefactos similares a los empleados en el armamento nuclear. Entiende el Gobierno de la República Argentina que dichas disposiciones aseguran el empleo de la energía nuclear como auxiliar indispensable en el proceso de desarrollo de la América Latina y representan, en consecuencia, la condición previa y fundamental para sentar las bases de un equilibrio aceptable de responsabilidades y obligaciones mutuas para las potencias nucleares y las no nucleares en materia de no proliferación...".

La ratificación, sin embargo, no se ha efectuado hasta la fecha, siendo Argentina el único país signatario que no lo ha hecho.

Debemos acotar además que Argentina se abstuvo en la votación de la Asamblea General de Naciones Unidas en relación a la recomendación que incluía el texto del TNP y ha declarado recientemente, a través del presidente de la Comisión Nacional de Energía Atómica (CNEA), contralmirante Carlos Castro Madero, que el Gobierno argentino "no firmará el tratado de no proliferación nuclear porque es totalmente discriminatorio y vulnera el principio de igualdad jurídica de todos los Estados"

La posición Argentina aparece, pues, congruente tanto en el plano universal como regional. Sin embargo sería interesante explicar la con-

44 Véase diario El Mercurio del 11 de marzo de 1979. 
cepción subyacente. No cabe la menor duda que Argentina posee en la actualidad un in discutible liderazgo nuclear en América Latina.

Argentina proyecta tener para el año 2.000, siete centrales nucleares capaces de producir energía eléctrica por un monto de 600 megavatios cada una. Bajo tal perspectiva el Gobierno trasandino acaba de aprobar la construcción de cuatro centrales que se agregarían a "Atucha 1", en servicio desde 1974; "Córdova" (o Cientral de Embalse de Río Tercero), entrará en funciones en 1981; y "Atucha 2". Todas las centrales nucleares argentinas son de tipo CANDU (Canadiense) y PHWR, vale decir, operantes con uranio natural y agua pesada.

Más aún, Argentina ha proyectado la construcción de una planta piloto de agua pesada, evitándose así todo control externo. Tal planta se insta-. laría en Neuquén, previéndose para 1980 Argentina estaría en condiciones de controlar el proceso de agua pesada para sus centrales nucleares. Como lo ha señalado Jorge Sábato, el plan nuclear argentino persigue "lograr capacidad autónoma de decisión en materia nuclear, y capacidad autónoma de producción de aquellos bienes y servicios nucleares que resulten técnica y económicamente factibles y convenientes ${ }^{3 / 45}$ Por lo demás, Argentina está en condiciones de hacer explosivos nucleares; de ahí la declaración efectuada al momento de la firma del Tratado de Tlatelolco.

Junto a este importante desarrollo, Argentina ha proseguido con una política de suscribir acuerdos con distintos países para el intercambio tecnológico en materia nuclear: con India en 1974, con Canadá en enero y febrero de 1976 y últimamente con el Peú, acuerdo en. virtud del cual se asegura la máxima participación peruana en el diseño, ingeniería, construcción y montaje de diversas plantas, varias de ellas con tecnología argentina, todo lo cual constituirá el Centro de Investigaciones Nucleares del Perú.

Esta política autónoma en materia nuclear ha sufrido presiones de parte de los EE.uU., una vez que asumió la presidencia el señor Carter. Es así como en la visita que efectuó el presidente Videla a Washington el 9 de septiembre de 1977, se insistió por parte de los Estados Unidos en la necesidad de que Argentina ratificara el Tratado de Tlatelolco. Posteriormente a raíz de una visita del secretario Vance a Buenos Aires en noviembre del mismo año, el Canciller Montes declaró la intención de su Gobierno de ratificar dicho instrumento regional.

t5 Cf. El Plan nuclear brasilero y la bomba atómica..., op. cit.. p. 82. Es necesario señalar que según el presidente de la CNEA existirian en Argentina reservas conocidas por 24 mil toneladas de concentrado de uranio, abrigándose esperanzas de que existan 400 mil toneladas. 
Otras declaraciones oficiales, del presidente de la Comisión de Energía Atómica de la Argentina o del canciller de dicho país en el Décimo Período Extraordinario de Sesiones de la Asamblea General dedicado al desarme, han afirmado una pronta ratificación sin que hasta la fecha se haya materializado ${ }^{46}$.

En el fondo la posición de Argentina frente al Tratado de Tlatelolco, y ello explica su no ratificación hasta ahora, es de desconfianza. Para Argentina el plan nuclear constituye un "objetivo nacional prioritario". Todo instrumento que directa o indirectamente limite su libertad en lo que Sábato llama "capacidad autónoma de decisión y producción", es considerado como contrario al objetivo nacional prioritario. La frase ya consagrada de que el TNP y Tlatelolco "desarman a los desarmados" expresa esta desconfianza.

Sábato niega que exista por parte de Argentina "una actitud recelosa" frente a los programas brasileños en materia de energía nuclear ${ }^{47}$; $\sin$ embargo, con respecto a otras fuentes alternativas de energía, es un hecho que el país trasandino se opuso a los dos acuerdos concluidos por el Brasil con Bolivia sobre gas natural y con Paraguay sobre coristrucción de la represa hidroeléctrica binacional en Itaipú. Es decir, la posición argentina frente a los instrumentos internacionales sobre no proliferación ha debido tener en cuenta los programas energéticos generales del Brasil.

Por último, Argentina en ciertas materias y en determinados períodos se ha caracterizado por una política nacionalista, contraria a las presiones externas. Ya en 1976, el general Juan E. Guglialmelli en un artículo titulado "Argentina. Plan Nuclear y presiones externas", escribía "...se materializan ya fuertes presiones externas que podrán trạbar, limitar o hasta hacer fracasar, en áreas esenciales, nuestro Programa Nuclear". "Debemos - concluía- estar decididos a defender los derechos en el tema de las salvaguardias y de los artefactos nucleares explosivos con fines pacíficos, así como disponer de adecuada capacidad negociadora para afrontar los posibles intentos gobierno a gobierno",48.

La posición del Brasil es algo distinta por lo menos desde un punto de vista formal, ya que ratificó el Tratado de Tlatelolico sin dispensa. Esta última modalidad significa que mientras no se cumplan con todas las

${ }^{46}$ Al respecto véanse también las gestiones realizadas por el Secretario de opanal ante los Ministros de Relaciones Exteriores Sr. Puig y Quijano en los años 1973 y 1976.

${ }^{47}$ Cf. El Plan nuclear brasilero y la bomba atómica ..., op. cit.. p. 82.

${ }^{48}$ Cf. Revista Estrategia $N^{\circ} 42$, septiembre-octubre 1976, págs. 5-19, p. 19. 
condiciones o requisitos estipulados en el artículo 28 del tratado, el país que ratifica no es parte en dicho instrumento y no participa en el Organismo (OPANAL).

Esta modalidad fue explicitada por el canciller Antonio Azeredo da Silveira el 18 de marzo de 1977, en carta dirigida al Secretario de OPANAL, en donde supedita la presencia plena del Brasil en el instrumento a la participación colectiva de todos los países de la región en el tratado y al compromiso inequívoco de las potencias nucleares y de las que tienen posesiones en América Latina con la firma y ratificación de los protocolos adicionales I y ir.

Si bien Brasil fue uno de los países que concurrió a la declaración del año 1963 y participó en todas las reuniones en donde se elaboró el tratado, al firmar dicho instrumento efectuó la siguiente declaración.

"El Gobierno del Brasil, al firmar el Tratado para la proscripción de las Armas Nucleares en la América Latina por medio del suscrito provisto de los Plenos Poderes necesarios, desea reafirmar su interpretación del sentido del Artículo 18 de dicho Instrumento. A juicio del Gobierno brasileño, el referido Artículo 18 faculta a los estados signatarios a realizar, por sus propios medios o en asociación con terceros, explosiones nucleares con fines pacíficos, inclusive aquellas que supongan artefactos similares a los empleados en los armamentos militares" ${ }^{\prime 49}$.

Este tipo de declaraciones, véase la anterior de Argentina, no han sido aceptadas en forma unánime. Tales declaraciones interpretan el Tratado de Tlatelolco en el sentido que no prohibiría las explosiones nucleares con fines pacíficos, hecho que demostraría que aquel instrumento afirma y garantiza el derecho soberano de todos los Estados miembros a la plena utilización pacífica de la en ergía nuclear.

Pero existe en este punto un equívoco que separa a Brasil y Argentina del resto de los Estados Partes en el tratado.

El artículo 17 del tratado afirma el derecho al uso pacífico de la energía nuclear; el artículo 18 por su parte permite la realización de explosiones de dispositivos nucleares con fines pacíficos -inclusive explosiones que presuponen artefactos similares a los empleados en el armamento nuclear - y la colaboración a terceros para los mismos fines. Sujeta, eso sí, tales explosiones a una serie de controles.

No obstante la existencia del artículo 18, México estima que en base al artículo 5, que define armas nucleares, las explosiones de artefactos

${ }^{49}$ Brasil firmó el tratado el 9 de mayo de 1967. 
nucleares para usos pacíficos están prohibidas por el Tratado de Tlatelolco ${ }^{50}$.

Brasil y Argentina afirmándose en el artículo 18 y argumentando que Tlatelolco prohíbe el ensayo, uso, recibo, emplazamiento de armas nucleares a diferencia del TNP que se refiere a armas nucleares $u$ otros artefactos nucleares explosivos, reafirman su derecho a realizar explosiones de dispositivos nucleares.

Brasil, por razones muy semejantes a las de Argentina, no forma parte del TNF, aduciendo su carácter discriminatorio. Para Brasil el TNP persigue "legitimar una distribución de poder inaceptable puesto que resulta del estado en que se encontraban los Estados, en lo que respecta a la aplicación de la tecnología nuclear, en la fecha de su firma. Como resultado de esta estratificación el tratado exige un estricto control de OIEA sobre la divulgación de la utilización pacífica del átomo, mientras que ninguna barrera crea a la prohibición vertical de los armamentos nucleares..."

Nuevamente encontramos en el continente americano esta necesidad de reafirmar la libertad en la decisión de cómo utilizar pacíficamente la energía nuclear. En el caso de Brasil la política nuclear ha sido el resultado de una evaluación de las necesidades energéticas del país, después de la crisis del petróleo, hecho que demostró que dicho país no podía continuar su programa de desarrollo económico en base a un combustible que se había tornado caro y de disponibilidad dudosa ${ }^{52}$.

Dentro de esa perspectiva suscribió, el 27 de junio de 1975 con la República Federal de Alemania, un acuerdo sobre la cooperación en el campo de los usos pacíficos de la energía nuclear. Brasil mantenía con Alemania desde 1969 un programa de cooperación en el campo nuclear, basado en el acuerdo general sobre cooperación en los sectores de la investigación científica y del desarrollo tecnológico.

El convenio de junio de 197.5 cumplía con una preocupación fundamental del Gobierno de Brasilia en el sentido de obtener la transferencia de la tecnología indispensable y adecuada para la implantación de una industria nuclear autónoma para fines pacíficos, pero abarcando el ciclo completo del combustible.

${ }^{50}$ Castañeda consigna el hecho de que la posición de México fue compartida por los Estados Unidos y la uRss, Cf. La no proliferación de las armas nucleares..., op. cit., pp. 56-57.

${ }^{51} \mathrm{Cf}$. Un ciocumento oficial sin firma titulado "El problema energético del Brasil: La necesidad de la opción nuclear".

${ }^{5-2}$ Sobre el impacto de la crisis de la energia en Brasil, véase Gall (N.), Energía atómica para el Brasil, peligro para todos. Revisla Estrategia $\mathrm{N}^{\circ} 42$, pp. $70-103$. 
Simultáneamente con el acuerdo se firmó un protocolo en materia industrial que aprueba directivas específicas para cada área de cooperación (minería, energía e investigación tecnológica). Igualmente se concluyeron varios puntos entre las Empresas Nucleares Brasileiras S. A. (Nuclebras) y diferentes empresas alemanas, en las cuales se prevén la formación de "joint-ventures" y la transferencia de tecnología y de equipos para ejecución de los diversos proyectos en cada una de las áreas de cooperación: prospección, extracción y tratamiento de minerales de uranio así como la producción de compuestos del mismo; fabricación de reactores y de otras instalaciones nucleares; enriquecimiento de uranio y servicios de enriquecimiento, y, producción de elementos combustibles y reprocesamiento de combustibles irradiados.

Para garantizar que la cooperación cumpla sus finalidades únicamente pacíficas, el acuerdo está basado en los siguientes fundamentos: afirmación del principio de no proliferación de armas nucleares, obligación de someter a las salvaguardias de la orEa todos los equipos, instalaciones y materiales nucleares; compromiso de no reexportar los referidos bienes y materiales a menos que el tercer país receptor haya firmado el acuerdo de salvaguardia; compromiso de no reexportar sin el acuerdo de la parte proveedora y por último, compromiso de dar protección física a los equipos, instalaciones y materiales nucleares.

Brasil y la República Federal de Alemania propusieron al Organismo de la Energía Atómica (OIEA), el texto de un acuerdo de salvaguardias que fue negociado con el Organismo en enero de 1976, y aprobado el 25 de febrero de 1976 por la junta de gobernadores del orEa. Según el Gobierno de Brasilia el texio suscrito entre Brasil, República Federal de Alemania y OIEA excede las exigencias de salvaguardias contenidas en el TNP, en el artículo 3. El sistema comprende la aplicación de salvaguardias no sólo al material, equipos e instalaciones, sino también abarca la transferencia de tecnología, la posibilidad de restablecimiento del acuerdo en caso de que si después de vencido, venga a ser utilizada la tecnología transferida; la adopción de medidas de protección física, la obligación de exigir la aplicación de salvaguardias a la exportación de terceros países, aunque se trate de países militarmente nucleares.

No obstante todos estos antecedentes la suscripción de este acuerdo provocó una fuerte reacción en los Estados Unidos, siendo más cautelosa la reacción soviética, pero no por ello positiva. Un editorial del New York Times, titulado "Locura atómica", definió el acuerdo como una "acción atolondrada que establecería una carrera de armas nucleares en América Latina...."

${ }^{53} \mathrm{Cf}$. Gall (N.), Energía atómica para el Brasil ...op. cil.. p. 70. 
La Unión Soviética expresó, por su parte, su preocupación por la proliferación nuclear, dejando entrever sus sospechas sobre las verdaderas intenciones de la República Federal de Alemania.

La respuesta del Brasil no se hizo esperar. Declaró, en primer lugar, ser un país pacífico, expresando que uno de los principios básicos de su política exterior era la creación de un clima favorable a la paz y a la seguridad internacional y al desarrollo económico de la humanidad.

Aclaró que Brasil es favorable al desarme pero siempre que éste no estimule a los Estados a procurarse medios y modos para fortalecer su posición militar.

Alegó ser parte en cinco tratados que directa o indirectamente se refieren a la cuestión de la proliferación de las armas nucleares, haciendo especial hincapié en que Brasil es parte en un tratado regional, Tlatelolco.

Exigió que se precisara el verdadero sentido de la no proliferación tendiente a impedir la diseminación de las armas atómicas, pero no la divulgación de la tecnología nuclear en beneficio de la humanidad. El acceso a la tecnología para la utilización de la energía nuclear, observando los controles adecuados, requisito cumplido en exceso en el acuerdo Brasil-Alemania, no debe estar sujeto a restricciones discriminatorias.

Precisando su posición con respecto a Tlatelolco expresó que de acuerdo con las normas de derecho internacional, Brasil se ha comprometido a no practicar actos que frustren los objetivos del tratado ${ }^{54}$, al cual corresponde la garantía de que los demás signatarios procederán de la misma forma.

Nos corresponde, por último, ver la concepción de Chile en esta tercera posición que hemos denominado Estados en situación especial.

Chile se encuentra en igual posición que el Brasil: ha ratificado el tratado sin dispensa ${ }^{55}$. Recordemos la importante participación del Gobierno chileno durante la elaboración del tratado, sin desconocer que fue uno de los Estados que concurrieron a la declaración de Presidentes de 1963.

No obstante todos estos antecedentes es un hecho que no existió durante las administraciones de los presidentes Eduardo Frei y Salvador Allende, voluntad política pór ratificar el Tratado de Tlatelolco. Así si el tratado fue aprobado por la Cámara de Diputados el 16 de septiembre de 1969, no existe un interés mayor en el Senado mientras Argentina no lo ratifique.

\footnotetext{
${ }^{54} \mathrm{La}$ declaración del Brasil hace referencia al artículo 18 de la Convención de Viena sobre Derecho de los tratados, en virtud del cual el Estado que hubiese firmado un tratado se compromete a no frustrar el objeto y fin del mismo.

${ }^{55}$ Chile aprueba el tratado por medio del D.L. 665 y lo promulga mediante el D.S. N ${ }^{\circ} 709$ de fecha 14 de diciembre de 1976.
} 
El Gobierno del Presidente Allende no demuestra mayor preocupación por agilizar el acuerdo del Congreso. En junio de 1973 el Presidente de la República responde al Secretario de opanal, expresando su imposibilidad de conseguir el acuerdo parlamentario por no tener una mayoría suficiente en el Senado.

Sin embargo, es necesario dejar constancia que a la Comisión de Relaciones Exteriores del Senado no llegó la opinión del sector Defensa, sin la cual era imposible tomar resolución alguna.

Posteriormente, el nuevo Gobierno ratificó sin dispensa el Tratado tomando en consideración de que Chile no debe comprometerse más allá de los compromisos adquiridos por Argentina y Brasil. Lógicamente Chile no es parte del TNP, y tampoco solicitó la calidad de observador en la Conferencia encargada de examinar dicho instrumento universal, realizada en Ginebra entre el 5 y 30 de mayo de $1975^{56}$.

De todas maneras conviene anotar que el ex ministro de Relaciones Exteriores de Chile, Patricio Carvajal, comunicó al Secretario de opanal, que si la Unión Soviética firma y ratifica el protocolo adicional II, Chile pasará a ser parte en el tratado y miembro de OPANAL.

Resumiendo, la posición de Argentina, Brasil y Chile en relación al Tratado de Tlatelolco es de desconfianza si aquél limitase el uso pacífico de la energía nuclear, o si su ámbito de aplicación fuese restringido tanto al interior del continente como fuera de él, en lo que se refiere a potencias nucleares de aquellas determinadas por el protocolo adicional $\mathrm{rr}$.

Los tres países están conscientes de la necesidad de diversificar la elección de los proveedores en materia de energía nuclear. Argentina ha llamado a una licitación internacional, suscribiendo acuerdos, por ejemplo, con la Kralt Werre Union A.G. (k.w.U.) y posteriormente con Sulzer Brothers Ltd. de Suiza.

Existe, por último, un cierto consenso frente a las presiones externas en el sentido que para "obtener y sostener esta autonomía tecnológica nuclear - que los países centrales no están dispuestos a aceptar de buen grado- Argentina necesita que muchos otros países, y particularmente los de América Latina, puedan alcanzar la suya propia...

La última concepción dentro del continente pertenece a los Estados Unidos. En ësta ocasión nos referiremos a la posición norteamericana frente al Tratado de Tlatelolco, analizando qué papel le asigna al instrumento regional.

${ }^{56} \mathrm{Cf}$. Fischer (G.), La Conferénce des parties chargées de l'exámen ... op. cit.. p. 11.

${ }^{57}$ Cf. Sábato (J.), El Plan nuclear brasilero ...op. cit., p. 82. 
Estados Unidos se incorpora al proceso de elaboración de Tlatelolco, en calidad de observador, sólo en el segundo período de sesiones. El 10 de diciembre de 1965, el representante de los Estados Unidos dirige una comunicación en donde precisa qué condiciones o requisitos deben poseer las zonas desnuclearizadas para recibir el apoyo de su país ${ }^{58}$. Las condiciones son las siguientes: la creación de tales zonas debe originarse dentro del área; la zona debe incluir a todos los Estados del área cuya participación se considera importante; la creación de la zona no debe poner en peligro acuerdos de seguridad; deben incluirse disposiciones tendientes a proporcionar una garantía razonable del cumplimiento de la desnuclearización de la zona contra eventuales violaciones.

Precisa al mismo tiempo que la zona desnuclearizada propuesta no debe incluir a las Islas Vírgenes, Puerto Rico, pues respecto de estas áreas, los Estados Unidos deben tener en cuenta políticas de desarme que afectan a otras potencias nucleares. La comunicación acepta la inclusión de la zona del Canal de Panamá (sin afectar los derechos de tránsito) y•de Guantánamo, si Cuba participa.

Estados Unidos aprobaba la idea de que se aplicaran las salvaguardias del olea para evitar' desviaciones de actividades, pero consideraba que para verificar las posibles introducciones de armas nucleares había que examinar otros procedimientos.

Estas ideas fueron reafirmadas el 29 de agosto de 1966 a través del embajador señor Fueton Freeman en carta dirigida al presidente de COPREDAl, señor Alfonso García Robles. Posteriormente los Estados Unidos hicieron un largo comentario sobre el texto de tratado ya aprobado en el seno del Comité de Desarme en el curso del año 1967. Especial hincapié hizo el embajador William Foster sobre el problema de las explosiones nucleares con fines pacíficos, concluyendo que el tratado prohibía a las Partes contratantes adquirir y ensayar artefactos nucleares explosivos con fines pacíficos ${ }^{59}$.

Esta actitud algo pasiva se modificó en el año 1968, cuando los Estados Unidos firmaron el protocolo adicional Ir, ratificándole el 12 de mayo de 1971. Sin embargo la posición norteamericana aparecía indecisa frente a las obligaciones que debían asumir los Estados que tenían de jure o de facto territorios en la zona desnuclearizada.

Tal situación no varió hasta la elección del presidente Carter, quien hizo suyo una de las recomendaciones del informe Linowitz, la cual proponía "alentar nuevas adhesiones al Tratado sobre Prohibición de Armas

\footnotetext{
${ }^{58}$ Véase el texto en García Robles (A.), El Tratado de Tlatelolco ...op. cit.. p. 160.

${ }^{59}$ Cf. Garcia Robles (A.), El Tratado de Tlatelolco ... op. cit.. pp. 293-295.
} 
Nucleares en América Latina y considerar la eliminación de sus objeciones al protocolo I de esta convención".

Tal recomendación suponía además que Estados Unidos debía condicionar cualquier transferencia de tecnología nuclear o material atómico al cumplimiento de estrictas medidas de protección internacionales, prefiriendo a Estados que fuesen parte en el TNP.

En el fondo las recomendaciones del informe Linowitz en esta materia implicaban afirmar que la no proliferación nuclear constituía uno de los mayores factores en el diseño de la política exterior de los Estados Unidos.

El presidente Carter aprovechó su presencia en el Consejo de la Organización de Estados Americanos para reafirmar este principio básico de su política exterior al decir que los Estados Unidos trabajarán "con todas las naciones a fin de detener la diseminación de la capacidad explosiva nuclear", y comunicaba que su país suscribiría el primer protocolo del Tratado de Tlatelolco.

Sin embargo, el representante de los Estados Unidos ante el Comité de Desarme interpretaba la futura adhesión norteamericana, estimando que tal hecho no menoscabaría "el derecho de los buques de la marina estadounidense a recalar en los puertos de esos territorios, ni tampoco afectaría a la libertad de navegación en la alta mar en las inmediaciones de América Latina ${ }^{\prime 160}$.

Esta interpretación efectuada por los Estados Unidos había sido debatida por la Comisión Preparatoria en su $40^{\mathrm{a}}$ sesión plenaria, celebrada el 7 de febrero de 1967. En efecto, el texto definitivo, artículo 1 letra b) omite cualquier referencia al término "transporte", no obstante que dicho término había figurado en uno de los textos alternativos. La ausencia de referencia en aquél podría conducir a sostener que el transporte de arma nuclear no estaba prohibido en el Tratado de Tlatelolco.

Esa posible conclusión es improcedente frente a una declaración interpretativa que efectuó la Comisión Preparatoria en febrero de 1967. En dicha ocasión la Comisión distinguió entre los sujetos que realizan el transporte; prohibiendo para las Partes Contratantes; considerando en cambio que ante un Estado que no sea Parte en el tratado, el transporte se identifica con el "tránsito", regido por los principios y normas del derecho internacional, pues el Tratado de Tlatelolco no contiene ninguna disposición al respecto ${ }^{61}$.

${ }^{60}$ Citado por Gros E. (H)., El Tratado de Tlatelolco. Diez años de aplicación 1967-1977... op. cit. p. 44.

${ }^{61}$ Argentina dejó constancia en el Acta final que a su juicio debía establecerse la prohibición de transporte incluyendo el tránsito de armas nucleares, pues de permitirse se violaría el espíritu del tratado. Citado por Garcia Robles (A.). El Tratado de Tlatelolco ... op. cit.. p. 248. 
Teniendo presente todos estos antecedentes la interpretación efectuada por los Estados Unidos, salvo en lo que se refiere a la posición de Argentina, parece compatible con la posición oficial mayoritaria de los Estados partes en Tlatelolco ${ }^{62}$.

Este proceso culminó el 26 de mayo de 1977 con la suscripción por parte de los Estados Unidos del Protocolo adicional i del tratado.

Conviene no obstante preguntarse los motivos que llevaron a Estados Unidos a suscribir el protocolo adicional i que asegurará la desnuclearización militar de Guantánamo, de la zona del Canal de Panamá, de las Islas Vírgenes y de Puerto Rico.

En primer lugar no cabe duda que constituye un principio de la política de los Estados Unidos el detener la diseminación de la capacidad nuclear en el mundo. Prueba de ello es su interés por el TNP, instrumento universal, y por el Tratado de Tlatelolco, instrumento regional. Si bien existe en los Estados Unidos un apoyo general al uso pacífico de la energía nuclear por parte de los países en vías de desarrollo, sujetan esta transferencia a medidas de protección muy exigentes.

Un segundo punto a destacar dice relación a la necesidad según los Estados Unidos de que el mayor número de países latinoamericanos suscriba y ratifique el Tratado de Tlatelolco. Tal necesidad es resentida especialmente frente a tres Estados: Argentina, Brasil y Cuba. Argentina y Brasil por el peligro de que posean armas nucleares, produciendo un desequilibrio político y militar en el continente. En lo que se refiere a Cuba, pues esta última al formar parte de Tlatelolco no agregaría mayores problemas a la seguridad de los Estados Unidos y favorecería un mejoramiento de las relaciones bilaterales entre ambos países.

Un tercer motivo, que es corolario del anterior, es que el Tratado de Tlatelolco constituye un nuevo instrumento de seguridad para el continente ante un desarrollo progresivo de la energía nuclear. Tales motivaciones están acompañadas de ciertos valores éticos, pues se insiste en la idea que la no proliferación permitirá edificar un mundo más pacífico y próspero.

Con ello hemos tratado de estudiar las diferentes concepciones continentales del Tratado de Tlatelolco, correspondiéndonos, ahora, analizar la inserción de Tlatelolco en el escenario mundial, tanto político como económico.

\footnotetext{
\$2 Véase al respecto la declaración del representante de México en la Conferencia de Desarme. Citado por Gros E. (H.), El Tratado de Tlatelolco. . op. cit., p. 45.
} 


\section{LA INSERCIÓN DE TLATELOLGO EN EL ESCENARIO MUNDIAL}

La inserción del Tratado de Tlatelolco en un escenario más amplio nos obliga a precisar tres aspectos importantes. En primer lugar la posición de dos países nucleares que han mantenido hasta hace muy poco una actitud de desconfianza con respecto al Tratado de Tlatelolco: Francia y la Unión Soviética. En segundo lugar, los aspectos económicos que indirectamente conlleva el desarrollo nuclear regional, fomentado y no suprimido por Tlatelolco $y$, por último, las proyecciones que un tratado regional tendiente a proscribir las armas nucleares puede significar para el desarme mundial.

Sabemos que el Tratado de Tlatelolco posee dos protocolos complementarios que persiguen objetivos distintos y cuyos destinatarios son también diferentes. Francia, hasta hace poco no había firmado el protocolo i y la Unión Soviética acaba de firmar el protocolo II, después de superar "algunas dudas... debido a algunos defectos bien conocidos de ese tratado ${ }^{963}$.

En cuanto a la posición de Francia, ella no deja de tener importancia, pues mantiene hasta la fecha territorios bajo su jurisdicción dentro de la región: Guyana francesa, Martinica y Guadalupe. Es cierto que Francia firmó el protocolo Ir el 18 de julio de 1973, pero según comentarios académicos franceses tal hecho aparecía como un gesto simbólico sin gran significación práctica ${ }^{64}$. En efecto, Francia ha mantenido un obstinado rechazo en el sentido de adherir al tratado de Moscú de 5 de agosto de 1963, que prohíbe los ensayos de armas atómicas en la atmósfera, y, en el mismo momento que firmaba el protocolo II del Tratado de Tlatelolco se iniciaba en el Pacífico, el séptimo período de experiencias nucleares francesas.

Esta ambigüedad en la posición de Francia ha adquirido con el tiempo una expresión menos equívoca a partir del primer semestre de 1978, con ocasión de la sesión especial de la Asamblea General de Naciones Unidas sobre el desarme. El 25 de enero de 1978, el Gobierno francés efectuó una declaración global sobre la materia en la cual propuso una acción a tres niveles: a nivel mundial, a nivel de regiones no nucleares y por último, a nivel de regiones nucleares ${ }^{65}$.

${ }^{\text {ti3 }}$ Cf. el discurso del ministro de Relaciones Exteriores, Gromyko, en la Asamblea General de las Naciones Unidas sobre desarme.

${ }^{13 .}$ Véase por ejemplo Rousseau (Ch.), Chronique des faits internationaux, R.G. D.I.P.. 1974, D. 740.

${ }^{65} \mathrm{Cf}$. Ministère des Affaires Etrangères, La politique Etrangère de la France. (Textes et documents), $1^{\text {er }}$ trimestre 1978, La documentation Frangaise, Paris 1978, pp. 36-38. 
En lo que se refiere a regiones no nucleares, objetivo perseguido por los signatarios de Tlatelolco, Francia consideró que el problema era doble: por una parte, que las zonas actualmente no nucleares permanezcan y, por la otra, que no se desarrolle una carrera ruinosa y peligrosa por la adquisición de armamentos convencionales. El primer aspecto implica el impedir la proliferación nuclear, tarea que recae sobre los Estados de la región, pero quienes deben recibir seguridades que al implementar tal tarea no serán objeto de discriminación ya sea desde un punto de vista del progreso, ya sea desde un punto de vista de su seguridad.

Las discriminaciones que pueden afectar al progreso de países o regiones no nucleares suponen la implementación de una política de no proliferación que el Gobierno de Francia califica de rigurosa y abierta. La primera calificación tiende a impedir los riesgos de la diseminación de armas nucleares y la segunda, persigue permitir el acceso a la utilización pacífica de la energía nuclear. En cambio las discriminaciones que pueden afectar la seguridad de los países o regiones concernidas obliga a las potencias nucleares militares a no extraer de la situación de aquellas ventajas políticas o militares. Bajo tal perspectiva Francia ha adoptado una actitud de principio positiva en relación a la creación de zonas desnuclearizadas respecto de continentes o de partes substanciales de los mismos ${ }^{66}$.

Por tal motivo, la República francesa se declara estar en condiciones para examinar bajo qué círcunstancias ella podría imponerse obligaciones precisas en la materia. El presidente Giscard d'Estaing, en el discurso pronunciado el 25 de mayo de 1978 en Naciones Unidas, precisó aún más estos puntos al afirmar que Francia deseaba firmar el protocolo I de Tlatelolco, en vista de lo cual entraría en contacto con las autoridades instituidas por el tratado para examinar las condiciones que podrían facilitar esta firma ${ }^{67}$.

Estos contactos se materializaron definitivamente a raiz del viaje oficial efectuado por el presidente Giscard d'Estaing a México entre el 28 de febrero y el 3 de marzo de 1979. En el comunicado conjunto, publicado el 2 de marzo ${ }^{68}$ el presidente de México señor López Portillo se felicita de la firma por parte de Francia, durante la visita del protocolo adicional $N^{\circ} 1$ al Tratado de Tlatelolco. Es interesante señalar que además del

${ }^{66}$ En una entrevista con la prensa el ministro de Relaciones Exteriores de Francia, señor De Guiringaud, condicionó el voto francés en favor de zonas desnuclearizadas a un acuerdo de todos los países concernidos, para precaverse de posibles críticas con respecto a la política de Francia en el continente europeo. Cf. Ministère des Affaires Etrangères. La politique étrangère de la France, op. cit., pp. 39-44.

${ }_{67}$ Véase el texto integro de este discurso en Ministère des Affaires Etrangères. La politique étrangère de Ia France, op. cit., $2^{\circ}$ trimestre 1978, pp. 63-71. 
comunicado conjunto, que manifiesta un gran número de convergencias de puntos de vista, ambos mandatarios firmaron once acuerdos de tipo económico, científico y cultural, destacándose entre ellos aquel que se refiere al desarrollo científico e industrial para la utilización de la energía nuclear con fines exclusivamente pacíficos y no explosivos.

La demora de Francia de suscribir el protocolo adicional $\mathrm{N}^{\circ} 1$, debe encontrar explicación en varios hechos: en primer lugar, porque tal suscripción implica limitar especialmente la política de disuasión de Francia, al otorgar en los hechos estatutos diferentes a parte de su territorio; segundo, porque Francia mantiene una política bastante audaz en materia de ventas de tecnología nuclear que no obstante las seguridades expresadas por vendedores o compradores es riesgosa y puede ser fuente de desequilibrios regionales.

La desconfianza de la Unión Soviética en relación a las obligaciones que impone el protocolo adicional $\mathrm{N}^{\circ} 2$ se explican por otras consideraciones que es necesario analizar. Firmado en Moscú el 18 de mayo de 1978, a raíz de una visita del presidente López Portillo, el gobierno de la Unión Soviética consideró del caso efectuar una serie de declaraciones interpretativas $^{69}$.

La primera dice relación a que la Unión Soviética considera como incompatible con el estatuto de desnuclearización la explosión de "nuclear devices for peaceful purposes". De una exégesis del Tratado de Tlatelolco algunos intérpretes han deducido que las explosiones de dispositivos nucleares con fines pacíficos, incluyendo explosiones que implican artefactos semejantes a los empleados en armamento nuclear, pueden realizarse por los Estados partes, los que a su vez podrían prestar su concurso en actividades realizadas por terceros pero siempre que no contravengan lo dispuesto en los artículos 1 y 5 del tratado latinoamericano. Igualmente los Estados miembros de Tlatelolco podrían recibir la colaboración de terceros Estados para efectuar tales explosiones. Por último y como argumento adicional y de lógica interpretación se hace mención al sistema de control, que entre sus funciones está el verificar que las explosiones con fines pacíficos sean compatibles con las disposiciones contenidas en el propio artículo $18^{70}$.

La posición de la Unión Soviética es compartida por los Estados Unidos y el Reino Unido ${ }^{71}$. Para los Estados Unidos "...la tecnología de la

${ }^{\text {b8 }}$ Cf. Ministère des Affaires Etrangères, La politique ètrangère de la France (1er trimestre 1979) ...op. cit.. pp. 110-114.

${ }^{69}$ Cf. Keesing's Contemporary Archives... p. 29022.

70 Tales son las interpretaciones de Argentina, Brasil y Nicaragua.

iVéase Gros Espiell (H.). En torno al Tratado de Tlatelolco ... op. cit.. p. 47. 
fabricación de artefactos nucleares explosivos es indistinguible de la tecnología para la fabricación de armas nucleares...". Ambos son susceptibles de liberar energía nuclear en forma no controlada, y por lo tanto, entran en la definición del artículo 5 del tratado (disposición que define "armas nucleares"), que prohíbe todos los artefactos nucleares explosivos.

El segundo punto de la declaración de la Unión Soviética se refiere a su negativa en aceptar la aplicación del tratado más allá del territorio de los Estados miembros, incluyendo el espacio aéreo y aguas territoriales establecidas de acuerdo al derecho internacional. A contrario sensu la Unión Soviética rechaza la zona establecida en el párrafo 2 del artículo 4. En efecto, la zona de aplicación del tratado es en la actualidad aquella a que se refiere el párrafo 1 del artículo 4, es decir, la suma de los territorios para los cuales el tratado está en vigor. Sin embargo, al cumplirse una serie de condiciones, tales como la aplicación del tratado por todos los países latinoamericanos, la ratificación de los Protocolos I y ir por todos los Estados involucrados y la celebración de los acuerdos con el Organismo Internacional de Energía Nuclear, la zona será mucho más amplia ${ }^{72}$. La posición soviética es consecuente con su política tradicional de no fomentar regímenes especiales sobre espacios territoriales comunes que tienden a limitar su capacidad de maniobra, atendido su estatuto.

El tercer punto de la declaración soviética se relaciona con el tránsito de armas nucleares, que según dicho Estado sería contrario a los objetivos del Tratado de Tlatelolco; como sabemos, el tratado no contiene ninguna prohibición al respecto, no obstante que en la $40^{\mathrm{a}}$ sesión plenaria, celebrada el 7 de febrero de 1967, la Comisión Preparatoria trató específicamente dicho problema. La Comisión en aquella ocasión distinguió "transporte" de "tránsito"; prohibiendo el primero, pues el transportador sería necesariamente uno de los Estados latinoamericanos ${ }^{73}$, y dejando sujeto

${ }^{72} \mathrm{El}$ artículo 4 párrafo 2 expresa: "Al cumplirse las condiciones previstas en el artículo 28, párrafo 1, la zona de aplicación del presente tratado será, además, la situada en el hemisferio occidental dentro de los siguientes límites (excepto la parte del territorio continental y aguas territoriales de los Estados Unidos de América): comenzando en un punto situado a $35^{\circ}$ latitud norte y $75^{\circ}$ longitud oeste; desde alli directamente al sur hasta un punto a $30^{\circ}$ latitud norte y $75^{\circ}$ longitud oeste; desde allí directamente al este hasta un punto a $30^{\circ}$ latitud norte $y$ $50^{\circ}$ longitud oeste; desde allí por una línea loxodrómica hasta un punto a $5^{\circ}$ latitud norte y $20^{\circ}$ longitud oeste; desde allí directamente al sur hasta un punto a $60^{\circ}$ latitud sur y $20^{\circ}$ longitud oeste; desde allí directamente al oeste hasta un punto a $60^{\circ}$ làtitud sur y $115^{\circ}$ longitud oeste; desde allí directamente al norte hasta un punto a $0^{\circ}$ latitud y $115^{\circ}$ longitud oeste; desde allí por una línea loxodrómica hasta un punto a $35^{\circ}$ latitud norte y $150^{\circ}$ longitud oeste; desde alli directamente al este hasta un punto a $35^{\circ}$ latitud norte y $75^{\circ}$ longitud oeste.

${ }^{73}$ Cf. García Robles (A.). El Tratado de Tlatelolco ...op. cit. pp. 247-248. 
el segundo a los principios y normas del derecho internacional en la materia, pues se trataría de terceros Estados. La posición soviética concuerda con una declaración de Argentina efectuada en el acta final del cuarto período de sesiones de la Comisión Preparatoria, en donde sostenía la necesidad de establecer la prohibición del transporte incluyendo el tránsito, por cuanto de permitirse se violaría el espíritu del tratado, cual era lograr la ausencia total de armamento nuclear en la región.

Insertar el Tratado de Tlatelolco en un contexto más universal nos conduce necesariamente a relacionarlo con la utilización pacífica de la energía nuclear en el plano regional. Tal utilización incluye referirse a la economía mundial, en especial a la transferencia de tecnología nuclear.

El artículo 17 del Tratado de Tlatelolco dispone que las obligaciones que han asumido los Estados miembros no menoscaba los derechos de aquellos para usar la energía nuclear con fines pacíficos en el desarrollo económico y progreso social ${ }^{74}$.

Con posterioridad en una serie de resoluciones de la Conferencia General de opanal se prevé para este último organismo la tarea de coordinar los esfuerzos en la utilización de la energía nuclear en el continente, agregando además la idea de planeación regional. Estas ideas de coordinación y planeación fueron explicitadas cuando la Conferencia General de OPANAL expresó la voluntad de que el organismo regional "planifique, sistematice, ordene y coordine los esfuerzos latinoamericanos para la plena y eficaz utilización pacífica de esta forma de en ergía"75.

Bajo tales perspectivas la Conferencia General ha dictado varias resoluciones cuyos objetivos van desde la creación de un fondo para financiar un programa de formación de técnicos latinoamericanos hasta aquellos más ambiciosos como la preparación de un programa de cooperación sobre la utilización pacífica de la energía nuclear en América Latina, con consultas al Organismo Internacional de Energía Atómica y a la Comisión Interamericana de Energía Nuclear.

Sin embargo, como ya lo hemos señalado en la segunda parte de este trabajo, la tendencia que se percibe en la región es la conclusión de acuerdos bilaterales que implican transferencia de tecnología nuclear, en algunos casos incluyendo el ciclo completo.

Argentina, Brasil y recientemente México, han suscrito acuerdos significativos con uno de los seis principales países poseedores de centrales

\footnotetext{
${ }^{74}$ Véase además el preámbulo y los artículos 1 y 18 del Tratado de Tlatelolco sin perjuicio de relacionarlo con el artículo $v$ del T.N.P.

${ }^{75} \mathrm{Cf}$. Declaración aprobada por la Conferencia General en la sesión dedicada a conmemorar el décimo aniversario del Tratado de Tlatelolco.
} 
nucleares (Estados Unidos, Alemania Federal, Francia, Inglaterra, Japón y la Unión Soviética).

Estos acuerdos de cooperación han aumentado en número y en justificaciones con ocasión de la diseminación en la región de la idea de que la energía nuclear sería una alternativa viable a la actual crisis energética. Tales ideas parten de varios supuestos, entre ellos de que existe y existirá un crecimiento inevitable del consumo de energía que no podrá paliarse con un mayor desarrollo de los combustibles fósiles.

A raíz de una serie de accidentes lo que ha demostrado la realidad de la posición de los ecologistas, la idea de acudir a otras fuentes energéticas tales como aquella proveniente de la fuerza hidráulica o de la energía solar ha ganado adeptos regionales. Sin embargo, en este punto, no se puede generalizar y cabe también mencionar elementos relacionados con opciones políticas nacionales. Así por ejemplo, en Brasil la opción hidroeléctrica, que ha sido prioritaria en el desarrollo de la producción de electricidad, se va acercando a sus límites económicos naturales. Manteniéndose la tasa nacional de crecimiento de consumo, se puede prever para el año 2000 la necesidad de una potencia instalada de producción de electricidad del orden de $180.000 .000 \mathrm{Kw}$ a $200.000 .000 \mathrm{Kw}$, demanda de cualquier forma superior al potencial hídrico existente en todo el Brasil aunque aquél fuera aprovechado integralmente desde el punto de vista económico y técnico.

Además de tales consideraciones no cabe la menor duda que la utilización de la energía nuclear por parte de un país constituye hoy en día un elemento de prestigio nacional y regional: el caso de Argentina es ejemplarizador al respecto.

El último aspecto que trataremos en esta inserción de Tlatelolco en el escenario mundial se relaciona con la proyección del tratado regional en los objetivos de un desarme general y completo.

En forma reiterada la Organización de las Naciones Unidas ha afirmado su convicción de que la creación de zonas libres de armas nucleares puede contribuir a tres objetivos: a la seguridad de los miembros de esas zonas; a la prevención de la proliferación de las armas nucleares y al logro de objetivos de un desarme global. Veamos cada uno de ellos.

En lo que se refiere a la seguridad de los estados miembros de una zona desnuclearizada sabemos que el Tratado de Tlatelolco la otorga mediante la suscripción, por parte de los Éstados nucleares, del Protocolo adicional II. Tal garantía también se encuentra explicitada, aunque de manera diferente, bajo la aplicación del T.N.P., en donde las tres potencias nucleares (Estados Unidos, Inglaterra y la Unión Soviética) efectuaron ante el Consejo de Seguridad una idéntica declaración en el sentido de asistir a 
un Estado no nuclear víctima de una agresión con empleo de armas nucleares o con amenazas de una tal agresión. Sin embargo, como lo señala por lo demás Georges Fischer ${ }^{76}$, esas declaraciones y la resolución del Consejo de Seguridad no crean ninguna nueva obligación en relación a aquellas consignadas en la Garta de San Francisco ${ }^{77}$. Quizás esas circunstancias fueron el origen de un proyecto de protocolo adicional presentado por once Estados no nucleares en la Conferencia destinada al examen del T.N.P. ${ }^{78}$. La conferencia desechó tal proyecto, haciéndose eco de la posición de los países socialistas en el sentido de invocar la resolución 2936 (xxvir) de la Asamblea General sobre renuncia a la amenaza o empleo de la fuerza y en especial a la prohibición de utilizar las armas nucleares, siendo además de la competencia del Cionsejo de Seguridad la adopción de medidas que obligarían a los Estados a aplicar esa resolución.

A pesar de las diferencias de garantías entre Tlatelolco y el T.N.P. en ambos casos aquellas son débiles. Estados Unidos, Inglaterra y la Unión Sovietica han efectuado declaraciones interpretativas al firmar el protocolo adicional il. Ya hemos estudiado la declaración soviética, correspondiéndonos referirnos a las declaraciones de Inglaterra y Estados Unidos. El Réino Unido se considera desligado de la obligación de no recurrir al empleo o a la amenaza de empleo de armas nucleares si una de las partes del tratado regional comete una agresión cualquiera con el apoyo de un Estado nuclear. Los Estados Unidos han efectuado una declaración semejante modificando los términos "agresión" por "ataque armado". El problema sigue vigente, pues cabe preguntarse quién juzgará la hipótesis de agresión y cuál será el valor de un compromiso de no utilización de armas nucleares si aquel compromiso puede ser denunciado en caso de guerra.

La segunda contribución, prevenir una proliferación de armas nucleares, aparece como más cierta, pues la prohibición establecida en el Tratado de Tlatelolco es absoluta en lo que a posesión y utilización se refiere. Es necesario recordar el problema del transporte o tránsito que indirectamente podría desnaturalizar este objetivo.

La tercera contribución, bastante más ambiciosa, se refiere a las proyecciones de zonas desnuclearizadas en un desarme global. La Asamblea General ha adoptado una declaración definiendo el concepto de zona desnuclearizada, resolución 3472 B. Según esa resolución varias son las con-

${ }^{76} \mathrm{Cf}$. La conferénce des parties chargées de l'exámen ...op. cit.. p. 39.

77 Véase resolución 255 (1968) Consejo de Seguridad.

${ }^{78} \mathrm{El}$ promotor fue Rumania. Sobre este proyecto se puede consultar a Fischer (G.). La conférence des parties chargées de l'examen... op. cit.. pp. 39-40. 
diciones que debe reunir esa zona: se debe tratar de una zona reconocida como tal por la Asamblea General; establecida por un grupo de Estados en el libre ejercicio de su soberanía; por medio de un tratado que defina el estatuto de la desnuclearización, el procedimiento para delimitar los límites geográficos de la zona y el sistema internacional de control y verificación. En relación a la zona así definida, los Estados nucleares deben asumir la obligación internacional de respetar las disposiciones del tratado que crea la zona.

Esta resolución, adoptada por una mayoría, ha contado con el voto en contra de los Estados Unidos, Francia y el Reino Unido y la abstención de la Unión Soviética y de la India. La posición de los países nucleares, esquemáticamente negativa, ha sido la siguiente: la definición es incompleta; es poco útil, pues sería necesario estudiar cada zona en particular; y es poco práctica, pues ningún Estado asume obligaciones que no sean el producto de libres negociaciones.

No obstante estas críticas no cabe la menor duda que el Tratado de Tlatelolco ha sido el origen de esta resolución, constituyéndose al mismo tiempo en el gestor de iniciativas tendientes a la creación de nuevas zonas libres de armas nucleares y relativas a regiones del Oriente Medio, Asi- Meridional, Africa y Pacífico Sur.

Si bien la multiplicación de posibles zonas desnuclearizadas podría ayudar al desarme global, no es menos cierto que ellas no aseguran un desarme general, vertical y horizontal. La posición sostenida por los países no nucleares en la Conferencia encargada de examinar el TNP sigue siendo válida y positiva. Todos los Estados que han depositado los instrumentos de ratificación del TNP deberían comprometerse por diez años a suspender todos sus ensayos nucleares, compromiso que otorgaría credibilidad al tratado universal e impediría interpretaciones peligrosas de tratados regionales al permitir explosiones nucleares pacíficas, que en el estado actual de la ciencia son difícilmente distinguibles de procesos con fines militares.

\section{CONGLUSIONES}

El Tratado de Tlatelolco puede constituir un nuevo desarrollo del sistema de seguridad interamericano, aun cuando la génesis y la realidad de este último sean muy diferentes al primero. La mantención de un relativo equilibrio forma parte de todo sistema de seguridad regional.

Para cumplir estos fines aparece necesario e indispensable que los Estados parte en Tlatelolco despejen el equívoco en las concepciones y consigan la adhesión de la totalidad de los estados de la región. 
La vigencia de un tratado regional que impone fuertes obligaciones a sus miembros es transitoria si la comunidad internacional no efectúa esfuerzos tendientes a implementar un desarme general y completo. Es necesario también aclarar las seguridades que otorgarán los Estados nucleares a países que han renunciado a la posesión y utilización de armas nucleares.

El Tratado de Tlatelolco ofrece un marco positivo para la utilización en forma coordinada de la energía nuclear con fines pacíficos. Esta nueva dimensión supone una voluntad política, en parte alejada de concepciones nacionalistas exacerbadas que desgraciadamente encuentran acogida hoy en día en la región. 